\title{
Brain Cell Membrane Function during Hypoxia in Hyperglycemic Newborn Piglets
}

\author{
JANE E. MCGOWAN, PETER J. MARRO, OM P. MISHRA, AND \\ MARIA DELIVORIA-PAPADOPOULOS
}

Departments of Pediatrics and Physiology, University of Pennsylvania School of Medicine, Philadelphia, Pennsylvania 19104

\begin{abstract}
To test the hypothesis that acute hyperglycemia reduces changes in cell membrane structure and function during cerebral hypoxia in the newborn, brain cell membrane $\mathrm{Na}^{+}, \mathrm{K}^{+}$-ATPase activity and levels of membrane lipid peroxidation products were measured in four groups of anesthetized, ventilated newborn piglets: normoglycemia/normoxia (control, group $1, n=12$ ), hyperglycemia/normoxia (group 2, $n=6$ ), untreated hypoxia (group 3, $n=10$ ), and hyperglycemia/hypoxia (group 4, $n=7$ ). Hyperglycemia (blood glucose concentration $20 \mathrm{mmol} / \mathrm{L}$ ) was induced using the glucose clamp technique. The hyperglycemic glucose clamp was maintained for $90 \mathrm{~min}$ before onset of hypoxia and throughout the period of hypoxia. Cerebral tissue hypoxia was induced in groups 3 and 4 by reducing fraction of inspired oxygen for $60 \mathrm{~min}$ and was documented by a decrease in the ratio of phosphocreatine to inorganic phosphate as measured using ${ }^{31} \mathrm{P}$-nuclear magnetic resonance spectroscopy. Blood glucose concentration during hypoxia in hyperglycemic hypoxic animals was $20.7 \pm 1.2 \mathrm{mmol} / \mathrm{L}$, compared with $10.3 \pm 1.7$ $\mathrm{mmol} / \mathrm{L}$ in untreated hypoxic piglets $(p<0.05)$. Peak blood lactate concentrations were not significantly different between the two hypoxic groups $(8.4 \pm 2.8 \mathrm{mmol} / \mathrm{L}$ versus $7.8 \pm 1.6$ $\mathrm{mmol} / \mathrm{L}$ ). In cerebral cortical membranes prepared from the
\end{abstract}

\section{ABSTRACT}

untreated animals, cerebral tissue hypoxia caused a $25 \%$ reduction in $\mathrm{Na}^{+}, \mathrm{K}^{+}$-ATPase activity compared with normoxic controls and an increase in conjugated dienes and fluorescent compounds, markers of lipid peroxidation. In contrast, $\mathrm{Na}^{+}, \mathrm{K}^{+}$ATPase activity and levels of lipid peroxidation products in hyperglycemic hypoxic animals were not significantly different from the values in control normoxic animals. These data suggest that in the newborn piglet model acute hyperglycemia reduces hypoxia-induced brain cell membrane dysfunction. (Pediatr Res 37: 133-139, 1995)

\section{Abbreviations}

NMR, nuclear magnetic resonance

$\mathrm{FiO}_{2}$, fraction of inspired oxygen

PCr, phosphocreatine

Pi, inorganic phosphate

$\mathbf{P C r} / \mathrm{Pi}$, ratio of phosphocreatine to inorganic phosphate

MABP, mean arterial blood pressure

GSH, reduced glutathione

ANOVA, analysis of variance

D25W, dextrose $25 \% \mathrm{wt} / \mathrm{vol}$ in water
In the brain, an hypoxic-ischemic insult leads to accumulation of lactate, tissue energy depletion and acidosis, and neuronal necrosis (1-4). Because glucose serves as the major energy source for the brain $(5,6)$, a number of studies have investigated the role of changes in glucose concentration in modifying the effects of cerebral hypoxia/ischemia. In adult animal models, outcome after cerebral ischemia was improved by mild hypoglycemia, and neurologic damage was more extensive in animals that were hyperglycemic during or after the insult $(2,7,8)$. These findings have been attributed to the effects of intracellular lactic acidosis resulting from increased anaerobic glycolysis in hyperglycemic animals $(7,9,10)$.

Received May 14, 1993; accepted August 29, 1994.

Correspondence and reprint requests: Jane E. McGowan, M.D., Neonatal-Perinatal Medicine, 2 Maloney, Hospital of the University of Pennsylvania, Philadelphia, PA 19104

Supported in part by National Institutes of Health Grants HD 20337 and HL 07027.
Studies by Myers and coworkers $(11,12)$ suggested that hyperglycemia also increased hypoxic/ischemic cerebral injury after cardiac arrest in juvenile monkeys.

In contrast, recent studies in newborn animals suggest that an acute increase in glucose concentration does not augment, and may reduce, the effects of cerebral hypoxia/ischemia. In newborn lambs, hyperglycemia had no effect on changes in intracellular $\mathrm{pH}$ or cerebral lactate concentrations during ischemia or early recovery (13) and prevented postasphyxial reduction in cerebral blood flow (14). Hyperglycemic newborn animals demonstrated less disturbance of cerebral ATP metabolism during partial cerebral ischemia than normoglycemic animals, although hyperglycemia was associated with more severe intracellular acidosis (15). Newborn rat pups had longer survival times after onset of anoxia if they received supplemental glucose (16). These differences in the response of newborn animals to hypoxia/ischemia may reflect differences 
in cerebral energy metabolism, glucose uptake, or lactic acid production (17).

We have shown in the fetus and newborn that cerebral hypoxia leads to alterations in cell membrane structure and function as demonstrated by increased brain cell membrane lipid peroxidation and decreased activity of the cerebral $\mathrm{Na}^{+}, \mathrm{K}^{+}$-ATPase (18-20). Based on previous studies that demonstrated that hyperglycemia improved survival and preserved brain structure in the newborn during hypoxia/ischemia, we hypothesized that hyperglycemia might also act to preserve brain cell membrane structure and function during cerebral hypoxia. Therefore, to test the hypothesis that acute hyperglycemia would reduce cerebral cellular injury in the newborn during hypoxia, we measured levels of membrane lipid peroxidation products as an index of alterations in brain cell membrane structure and $\mathrm{Na}^{+}, \mathrm{K}^{+}$-ATPase activity as an index of cell membrane function in newborn piglets after exposure to hypoxia alone or hypoxia with accompanying hyperglycemia.

\section{METHODS}

Studies were performed in newborn piglets 3-7 d old. The experimental protocol was approved by the University of Pennsylvania Institutional Animal Care and Use Committee. Anesthesia was induced with $4 \%$ halothane; during surgery, animals breathed spontaneously and anesthesia was maintained with $0.8-1.0 \%$ halothane. Using lidocaine $1 \%$ for local anesthesia, an endotracheal tube was placed via a tracheotomy. Polyvinyl chloride catheters were placed in the aorta via one femoral artery for monitoring of blood pressure and withdrawal of blood samples and in the inferior vena cava via each of the femoral veins for administration of drugs and infusion of glucose. After completion of surgery, halothane was withdrawn, and the animals were given fentanyl, 25-30 $\mu \mathrm{g} / \mathrm{kg}$, and tubocurarine, $2 \mathrm{mg} / \mathrm{kg}$, and placed on a volume-cycled small animal ventilator (Harvard Apparatus, Inc., South Natick, MA). Anesthesia during the study was maintained with $21 \%$ $\mathrm{O}_{2} / 79 \% \mathrm{~N}_{2} \mathrm{O}$ and fentanyl $25-30 \mu \mathrm{g} / \mathrm{kg}$ administered every 45-60 min. Animals were kept on a servocontrolled warming blanket to maintain body temperature at $38.5^{\circ} \mathrm{C}$. Initial ventilator settings were selected to achieve normal arterial blood gases (arterial $\mathrm{PcO}_{2}$ 4.7-6.0 $\mathrm{kPa}$; arterial $\mathrm{Po}_{2}, 10-17 \mathrm{kPa}$ ). Arterial blood gases were measured at the beginning and end of each study period and as needed to monitor the animal's status and maintain desired blood gas values for each study group.

After surgery and a 30-min stabilization period, animals were divided into one of four groups. Two groups served as normoxic controls. Normoglycemia/normoxia (i.e. control) animals (group 1) were ventilated to maintain normal blood gases for an additional $90 \mathrm{~min}$. Blood glucose and lactate concentrations were measured every $15 \mathrm{~min}$. Hyperglycemia/normoxia animals (group 2) received a bolus of D25W followed by a continuous infusion of D25W to establish and maintain a blood glucose concentration of $20 \mathrm{mmol} / \mathrm{L}$. Glucose and lactate concentrations were measured every $10-15 \mathrm{~min}$, and the pump rate was adjusted to achieve the desired value by using a modification of the glucose clamp technique $(21,22)$. Hyperglycemia was maintained for $90 \mathrm{~min}$; ventilator settings were adjusted as needed to maintain normal blood gas values as described above.

The two remaining groups of piglets were subjected to cerebral hypoxia, which was documented by ${ }^{31} \mathrm{P}-\mathrm{NMR}$ spectroscopy as a $30 \%$ decrease in $\mathrm{PCr} / \mathrm{Pi}$ (23). This value was based on our previous study, which showed that $\mathrm{Na}^{+}, \mathrm{K}^{+}$ATPase activity decreased when $\mathrm{PCr} / \mathrm{Pi}$ was reduced by at least $30 \%$. Piglets in the remaining two groups were designated as group 3 (untreated hypoxia) and group 4 (hyperglycemia/ hypoxia). After catheter placement in these animals, the scalp was removed using electrocautery to enhance acquisition of the NMR signal. The animal was transferred to a specially designed cradle, and the NMR coil was placed directly on the skull. The animal was then placed in the bore of a superconducting magnet for the remainder of the study (see below). After placement in the magnet, stabilization, and normalization of blood gases on mechanical ventilation, three baseline ${ }^{31} \mathrm{P}$ NMR spectra were obtained. Arterial blood glucose and lactate concentrations were measured at 10 -min intervals during the last $30 \mathrm{~min}$ of the baseline period.

After baseline measurements were collected, cerebral hypoxia was induced in group 3 animals by reducing the $\mathrm{FiO}_{2}$ until a decrease was observed in $\mathrm{PCr} / \mathrm{Pi}$, indicating the onset of cerebral tissue hypoxia. The newly established $\mathrm{PCr} / \mathrm{Pi}$ was maintained for $60 \mathrm{~min}$. During the hypoxia period, normal saline was infused via a venous catheter at a rate comparable to the average rate used for the glucose clamp in the hyperglycemic animals. Arterial samples for measurement of blood glucose and lactate concentrations were obtained every $15 \mathrm{~min}$. Blood gas values were determined after $10 \mathrm{~min}$ of hypoxia and at the end of the study.

Group 4 animals were made hyperglycemic after baseline data were obtained by administering a bolus and continuous infusion of D25W as in group 2. Hyperglycemia (blood glucose concentration $20 \mathrm{mmol} / \mathrm{L}$ ) was maintained for $90 \mathrm{~min}$, then the $\mathrm{FiO}_{2}$ was reduced and cerebral hypoxia established and monitored as in group 3. The glucose clamp was continued throughout the hypoxic period. Arterial blood samples were obtained for glucose, lactate, and blood gases as in group 3.

Arterial blood gases were measured during each experiment using a Corning model 178 blood gas analyzer (CIBA-Corning Diagnostics Corp., Medfield, MA). Blood glucose and lactate concentrations were measured using a YSI 2300 dual analyzer (Yellow Springs Instruments Co., Yellow Springs, $\mathrm{OH}$ ). End tidal $\mathrm{CO}_{2}$ and MABP were monitored continuously throughout the study. At the end of each study, cerebral cortex was obtained and rapidly frozen in liquid nitrogen for further biochemical analysis. Samples were stored at $-80^{\circ} \mathrm{C}$ until analysis could be completed.

NMR. ${ }^{31} \mathrm{P}$-NMR spectroscopy of the cerebral cortex was performed using a $2.7-$ Tesla $25-\mathrm{cm}$ diameter horizontal-bore superconducting magnet and spectrometer (Otsuka Electronics, Fort Collins, CO). A single turn double-tuned 3-cm diameter surface coil with a resonant frequency of $116 \mathrm{MHz}$ for proton and $46.9 \mathrm{MHz}$ for phosphorus was centered over the vertex of the skull. Spectra were obtained using a bandwidth of $4000 \mathrm{~Hz}$ and a repetition time of $4 \mathrm{~s}$. Twenty-five to 60 free induction decays were accumulated for each scan, yielding a time reso- 
lution of 1.5-4 mins. A deconvolution difference baseline correction was applied to the spectra, as were linewidth broadening of $8-10 \mathrm{~Hz}$ and zero and first-order phase corrections.

Analysis of spectra. Peak areas were calculated using a manual peak selection curve-fitting method. The ratio of the area of the $\mathrm{PCr}$ peak to the area of the $\mathrm{Pi}$ peak $(\mathrm{PCr} / \mathrm{Pi})$ was calculated as an index of the state of cerebral oxidative phosphorylation during each of the study periods. Inasmuch as the absolute value of the baseline $\mathrm{PCr} / \mathrm{Pi}$ value varied from animal to animal, the $\mathrm{PCr} / \mathrm{Pi}$ values measured after changes from baseline conditions were divided by the corresponding baseline value and multiplied by 100 to obtain a value for the new $\mathrm{PCr} / \mathrm{Pi}$ expressed as a percent of baseline. Intracellular $\mathrm{pH}$ was calculated from the chemical shift difference $(\delta)$ between the $\mathrm{PCr}$ and Pi peaks (24).

Biochemical analysis. Brain cell membranes were prepared according to the methods of Harik et al. (25). Frozen cortex was homogenized in $10 \mathrm{mM}$ Tris- $\mathrm{HCl}$ buffer containing $0.3 \mathrm{M}$ sucrose and $0.5 \mathrm{mM}$ EDTA. The $\mathrm{pH}$ of all buffer solutions was adjusted to 7.40 . The homogenate was centrifuged at $1000 \times$ $g$ for $10 \mathrm{~min}$. The supernatant was centrifuged at $40000 \times g$ for $60 \mathrm{~min}$. The resultant pellet was homogenized in $10 \mathrm{mM}$ Tris- $\mathrm{HCl} / 0.5 \mathrm{mM}$ EDTA buffer and centrifuged at $40000 \times \mathrm{g}$ for $60 \mathrm{~min}$. The final pellet was resuspended in $10 \mathrm{mM}$ Tris $/ 0.5$ mM EDTA buffer, diluted to a concentration of $1 \mathrm{mg}$ protein/ $\mathrm{mL}$, and used as the membrane fraction. This fraction contains synaptic membranes as well as membranes from neuronal cell bodies, glia, and mitochondria.

$\mathrm{Na}^{+}, \mathrm{K}^{+}$-ATPase activity was determined as previously described (18). The rate of ATP hydrolysis was determined in a $1-\mathrm{mL}$ reaction mixture of $50 \mathrm{mM}$ Tris- $\mathrm{HCl}$ buffer, $100 \mathrm{mM}$ $\mathrm{NaCl}, 3 \mathrm{mM}$ ATP, $3 \mathrm{mM} \mathrm{MgCl}$, and $80 \mu \mathrm{g}$ of membrane protein in the presence and absence of ouabain by the spectrophotometric measurement of the amount of Pi released. The ouabain-sensitive activity was interpreted as the $\mathrm{Na}^{+}, \mathrm{K}^{+}$ATPase activity and expressed as $\mu \mathrm{mol} \mathrm{Pi} / \mathrm{mg}$ protein $/ \mathrm{h}$.

Levels of conjugated dienes and fluorescent compounds in the membrane preparation were determined as an index of the degree of brain cell membrane lipid peroxidation. Lipids were extracted from the membranes with 2:1 chloroform:methanol containing $0.005 \%$ butylated hydroxytoluene and $0.5 \mathrm{mM}$ EDTA using a modification of the Folch extraction (26). Conjugated dienes were determined by measuring the absorbance spectra of the membrane lipid extract at $200-300 \mathrm{~nm}$ as described by Recknagel and Glende (27). The difference spectrum at $232 \mathrm{~nm}$ was used to determine the final conjugated diene concentration in $\mu \mathrm{mol} / \mathrm{g}$ brain. The value in control normoxic brain (group 1) was set to zero and served as a reference value (19). Concentrations of fluorescent compounds were determined using the method of Dillard and Tappel (28) by exciting the lipid extract at $360 \mathrm{~nm}$, measuring emission at $435 \mathrm{~nm}$, and comparing this value with a quinine sulfate standard. Both conjugated diene and fluorescent compound values are expressed per gram of brain (lipid equivalent) and are independent of tissue water content.

Statistics. All values are shown as mean $\pm \mathrm{SD}$. Comparisons between study periods for each group of animals were performed using one-way ANOVA with repeated measures. If the
ANOVA showed statistical significance, study periods were compared using the paired $t$ test with Bonferroni's correction. Biochemical data between groups were compared with a oneway ANOVA and unpaired $t$ test with Bonferroni's correction.

\section{RESULTS}

A total of 35 piglets were studied. Twelve were assigned to the normoglycemia/normoxia group (group 1), six to the hyperglycemia/normoxia group (group 2), 10 to the untreated hypoxia group (group 3), and seven to the hyperglycemia/ hypoxia group (group 4). Physiologic data from the four experimental groups are shown in Table 1 . The values shown for the baseline and hyperglycemia periods are the means of the average value for each animal; values during hypoxia are the means of the values obtained in each animal at the specified time. There were no significant differences in the baseline blood gas values or mean arterial blood pressure among the four experimental groups, nor was there any significant change during normoxic hyperglycemia (groups 2 and 4). During hypoxia, arterial $\mathrm{pH}$ and arterial $\mathrm{Po}_{2}$ were significantly lower than baseline in both groups 3 and 4 , but there was no significant difference between the two hypoxic groups. Arterial $\mathrm{PCO}_{2}$ did not change during hypoxia in either group, even though $\mathrm{pH}$ decreased significantly, indicating the presence of a metabolic acidosis. MABP decreased gradually in groups 3 and 4 during the $60 \mathrm{~min}$ of hypoxia. The MABP at the end of hypoxia was significantly lower than the baseline value in both groups; however, MABP remained in the physiologic range for the majority of the animals.

Mean blood glucose and lactate concentrations in each experimental group for each of the study periods are compared in Table 2. By random selection, the animals assigned to hypoxia alone (group 3) had higher baseline blood glucose values than the animals in the hyperglycemia/hypoxia group, but all values were within the normal range observed in piglets at this age. Lactate concentrations were similar in all four groups. Figure 1 summarizes the changes in blood glucose concentrations with time in the two groups of animals exposed to cerebral hypoxia. In the untreated hypoxia group (group 3), glucose concentration increased significantly to $8.8 \pm 2.6$ $\mathrm{mmol} / \mathrm{L}$ during hypoxia but was significantly lower throughout than the value maintained in the hyperglycemia/hypoxia group. In group 4 , the glucose concentration was $>16.7 \mathrm{mmol} / \mathrm{L}$ within 30 min of starting the glucose clamp and was maintained between 16.5 and $22 \mathrm{mmol} / \mathrm{L}$ throughout the remainder of the study in all animals. Blood lactate concentrations in group 3 increased with duration of hypoxia, reaching a peak of $8.4 \pm 2.8 \mathrm{mmol} / \mathrm{L}$ at $60 \mathrm{~min}$ of cerebral hypoxia. Blood lactate concentrations in group 4 also increased during hypoxia. Neither the maximum concentration reached nor the increase in lactate concentration was significantly different from those in group 3.

Hyperglycemia alone had no significant overall effect on cerebral oxidative phosphorylation. During the 90 -min glucose clamp period, three of six animals demonstrated transient fluctuations in $\mathrm{PCr} / \mathrm{Pi}$, but the mean value during hyperglycemia was not different from baseline (data not shown). As 
Table 1. Physiologic data

\begin{tabular}{|c|c|c|c|c|}
\hline \multirow[b]{2}{*}{ Study period } & \multicolumn{4}{|c|}{ Study group } \\
\hline & $1(n=12)$ & $2(n=6)$ & $3(n=10)$ & $4(n=7)$ \\
\hline \multicolumn{5}{|l|}{ Arterial $\mathrm{pH}$} \\
\hline Baseline & $7.39 \pm 0.05$ & $7.39 \pm 0.05$ & $7.39 \pm 0.06$ & $7.46 \pm 0.10$ \\
\hline Hyperglycemia & & $7.36 \pm 0.03$ & & $7.38 \pm 0.07$ \\
\hline Hypoxia (15 min) & & & $7.34 \pm 0.05$ & $7.32 \pm 0.12$ \\
\hline Hypoxia (60 min) & & & $7.11 \pm 0.20$ & $7.17 \pm 0.11$ \\
\hline \multicolumn{5}{|l|}{ Arterial $\mathrm{PCO}_{2}(\mathrm{kPa})$} \\
\hline Baseline & $5.3 \pm 0.5$ & $5.7 \pm 0.9$ & $4.9 \pm 0.7$ & $4.8 \pm 1.2$ \\
\hline Hyperglycemia & & $5.6 \pm 0.5$ & & $5.2 \pm 1.2$ \\
\hline Hypoxia (15 min) & & & $4.9 \pm 0.5$ & $4.7 \pm 1.3$ \\
\hline Hypoxia (60 min) & & & $4.8 \pm 0.9$ & $5.7 \pm 1.3$ \\
\hline \multicolumn{5}{|l|}{ Arterial $\mathrm{Po}_{2}(\mathrm{kPa})$} \\
\hline Baseline & $12.0 \pm 2.5$ & $11.8 \pm 2.3$ & $14.0 \pm 1.0$ & $15.5 \pm 3.9$ \\
\hline Hyperglycemia & & $11.7 \pm 1.6$ & & $13.0 \pm 3.0$ \\
\hline Hypoxia (15 min) & & & $2.5 \pm 0.5^{*}$ & $4.0 \pm 1.4^{*} \dagger$ \\
\hline Hypoxia (60 min) & & & $2.9 \pm 0.4^{*}$ & $3.3 \pm 0.8^{*}$ \\
\hline \multicolumn{5}{|l|}{ MABP (mm Hg) } \\
\hline Baseline & $88 \pm 18$ & $83 \pm 16$ & $107 \pm 18$ & $94 \pm 18$ \\
\hline Hyperglycemia & & $84 \pm 11$ & & $101 \pm 27$ \\
\hline Hypoxia (15 min) & & & $55 \pm 11^{*}$ & $62 \pm 13^{*}$ \\
\hline Hypoxia (60 min) & & & $62 \pm 9^{*}$ & $65 \pm 24^{*}$ \\
\hline
\end{tabular}

Study group $1=$ control; group $2=$ hyperglycemia/normoxia; group $3=$ untreated hypoxia; group $4=$ hyperglycemia/hypoxia.

$* p<0.05$ vs corresponding baseline value.

$\dagger p<0.05$ vs group 3 .

Table 2. Changes in glucose and lactate concentrations during hypoxia

\begin{tabular}{lcccc}
\hline & \multicolumn{4}{c}{ Study group } \\
\cline { 2 - 5 } Study period & 1 & 2 & 3 & 4 \\
\hline Glucose $(\mathrm{mmol} / \mathrm{L})$ & & & & \\
$\quad$ Baseline & $5.3 \pm 1.3$ & $3.7 \pm 1.4$ & $5.0 \pm 1.4$ & $4.3 \pm 1.0$ \\
$\quad$ Hyperglycemia & & $19.9 \pm 1.2^{*}$ & & $20.2 \pm 1.7^{*}$ \\
$\quad$ Hypoxia $\dagger$ & & & $8.9 \pm 2.8^{*}$ & $20.5 \pm 1.4^{*} \ddagger$ \\
Lactate $(m m o l / L)$ & & & & \\
$\quad$ Baseline & $1.4 \pm 0.4$ & $0.9 \pm 0.4$ & $1.6 \pm 0.7$ & $2.2 \pm 0.8$ \\
$\quad$ Hyperglycemia & & $1.4 \pm 0.2$ & & $2.8 \pm 1.0$ \\
$\quad$ Hypoxia $\dagger$ & & & $8.8 \pm 2.6^{*}$ & $7.8 \pm 1.6^{*}$ \\
\hline
\end{tabular}

Study group 1 = control; group 2 = hyperglycemia/normoxia; group $3=$ untreated hypoxia; group $4=$ hyperglycemia/hypoxia. Values are mean $\pm \mathrm{SD}$.

${ }^{*} p<0.05 v s$ corresponding baseline value.

$\dagger$ Value during last $15 \mathrm{~min}$.

$\ddagger p<0.05$ vs group 3 .

shown in Figure 2, PCr/Pi during hypoxia was reduced to $47 \pm$ $22 \%$ of baseline (range $10 \%-67 \%$ for the 10 animals studied) in group 3 and $46 \pm 25 \%$ of baseline (range $13 \%-68 \%$ for the seven animals studied) in group 4. As expected, intracellular $\mathrm{pH}$ decreased during hypoxia from $7.15 \pm 0.07$ to $6.83 \pm 0.08$ $(p<0.05)$ in group 3 and from $7.11 \pm 0.14$ to $6.84 \pm 0.20$ $(p<0.05)$ in group 4 . The decrease in pHi from baseline was similar in both groups.

Biochemical data. Figure 3 compares the $\mathrm{Na}^{+}, \mathrm{K}^{+}$-ATPase activity in brain cell membranes prepared from each of the four groups of animals. $\mathrm{Na}^{+}, \mathrm{K}^{+}$-ATPase activity was significantly reduced during cerebral hypoxia alone (group 3 ). As in our previous study (20), the magnitude of the decrease in $\mathrm{Na}^{+}, \mathrm{K}^{+}$. ATPase activity correlated with the magnitude of the decrease in $\mathrm{PCr} / \mathrm{Pi}$ in each animal. However, in the animals subjected to a hyperglycemic glucose clamp before and during hypoxia, $\mathrm{Na}^{+}, \mathrm{K}^{+}$-ATPase activity was preserved at control levels even

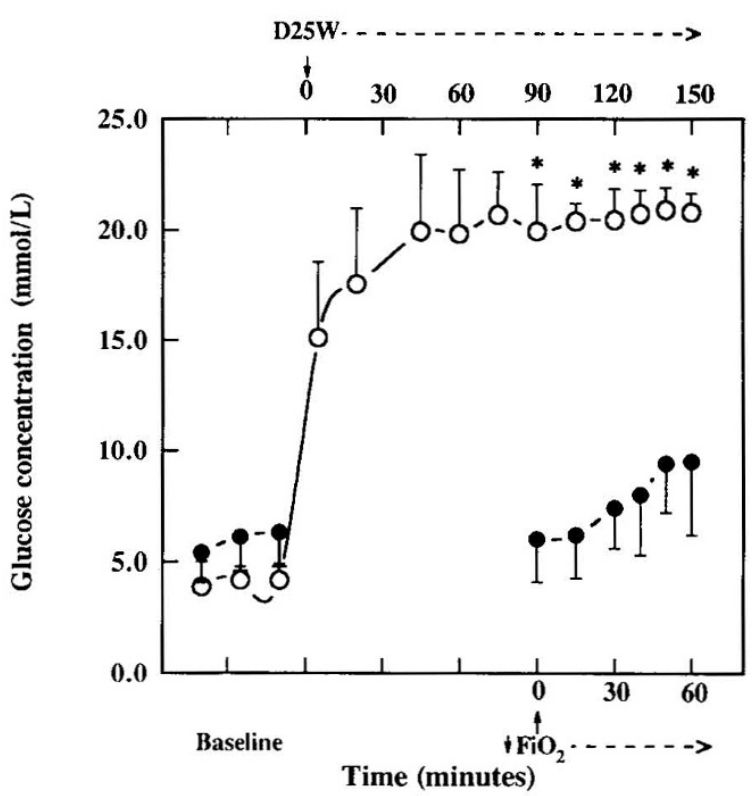

Figure 1. Changes in blood glucose concentrations with time for piglets subjected to untreated hypoxia (group $3, \bullet$ ) or hyperglycemia/hypoxia (group 4,0 ). Arrows indicate points at which glucose infusion (D25W) was started in group 4 and hypoxia induced in both groups by lowering the $\mathrm{FiO}_{2}$. Values are mean \pm SD. ${ }^{*}, p<0.05$ for group 3 vs group 4 .

though $\mathrm{PCr} / \mathrm{Pi}$ was reduced, regardless of the magnitude of the change in $\mathrm{PCr} / \mathrm{Pi}$. Levels of fluorescent compounds and conjugated dienes, which are indicators of the presence of membrane lipid peroxidation, were significantly elevated in the untreated hypoxia group compared with the two groups of normoxic controls (Fig. 4). Fluorescent compounds and conjugated dienes in membranes prepared from the hyperglycemic/hypoxic newborn piglets were not significantly different from values in group 1 . As a result, levels of lipid peroxidation 


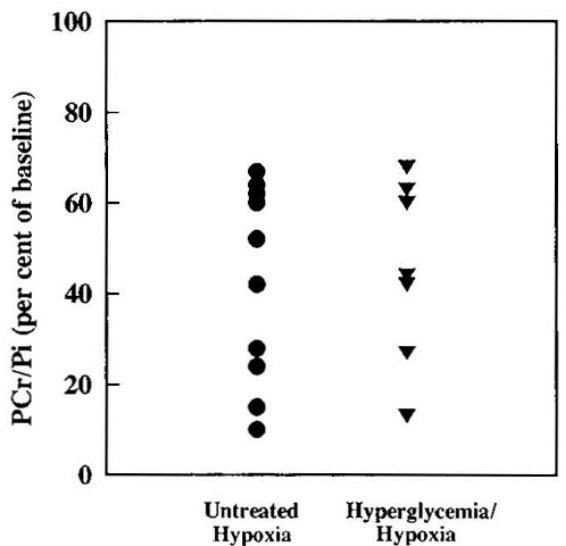

Figure 2. $\mathrm{PCr} / \mathrm{Pi}$ values during hypoxia expressed as percent of corresponding baseline value. $\bullet$, Untreated hypoxic piglets (group 3); $\mathbf{\nabla}$, hyperglycemic/ hypoxic piglets (group 4). Each point corresponds to the mean for a single animal.



Figure 3. $\mathrm{Na}^{+}, \mathrm{K}^{+}$-ATPase activity in cell membranes prepared from the cerebral cortex of piglets in each experimental group. $\square$, Normoxic controls (group 1); $\mathbb{\mathbb { N }}$, normoxia/hyperglycemia (group 2); $\mathbf{\square}$, untreated hypoxia (group 3); 圈, hyperglycemia/hypoxia (group 4). Values are mean $\pm \mathrm{SD} .{ }^{*}, p<0.05$ vs control (group 1); ${ }^{* *}, p<0.05$ vs group 3.

products were significantly lower in group 4 animals than levels measured in group 3. Ninety min of hyperglycemia alone had no significant effect on brain cell membrane $\mathrm{Na}^{+}, \mathrm{K}^{+}$-ATPase activity or membrane lipid peroxidation products.

\section{DISCUSSION}

In the present study, administration of $25 \%$ dextrose to maintain blood glucose at $20 \mathrm{mmol} / \mathrm{L}$ before and during an acute hypoxic insult prevented hypoxia-induced changes in brain cell membrane $\mathrm{Na}^{+}, \mathrm{K}^{+}$-ATPase and membrane lipids in newborn piglets. This finding is consistent with previous studies in newborn animals that demonstrated that hyperglycemia either had no significant effect on the cerebral response to hypoxia/ischemia $(13,29)$ or improved outcome as indicated by improved survival $(16,30)$ or decreased infarct size (31). In contrast, several studies of cerebral hypoxia/ischemia in adult animals found that hyperglycemia during or after the insult is associated with decreased survival $(32,33)$, significant increases in cerebral lactate concentration, and reduced intracel-
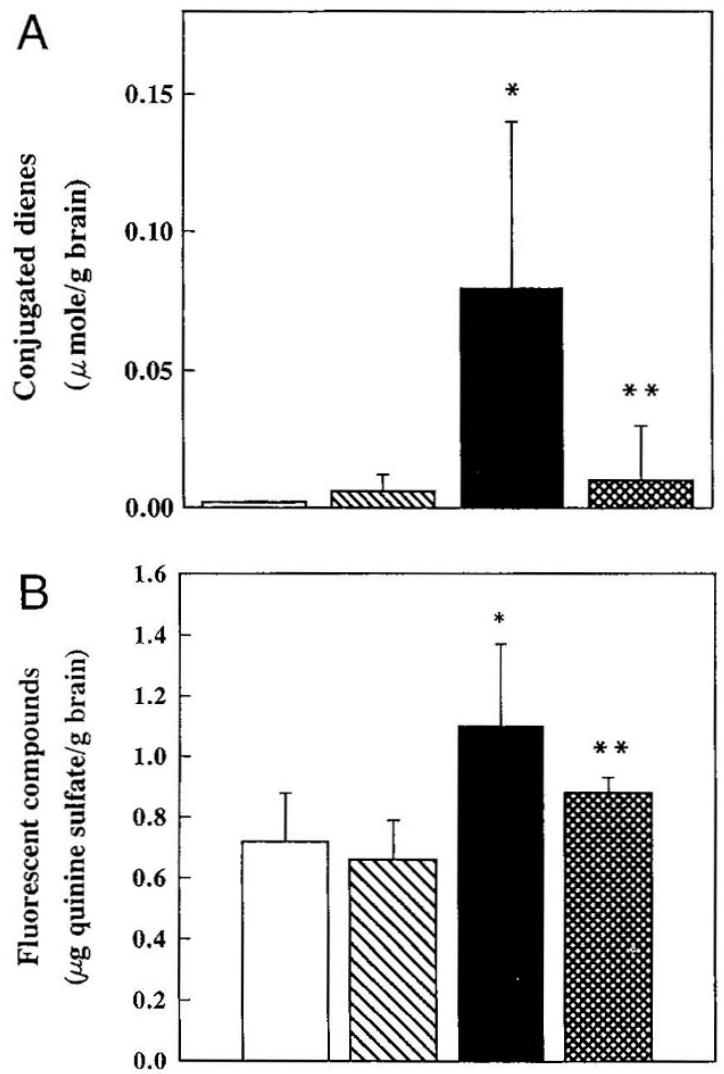

Figure 4. Levels of brain cell membrane lipid peroxidation products [conjugated dienes $(A)$, and fluorescent compounds $(B)]$ in each of the study groups. Bars are the same as in Figure 3. Values are mean \pm SD. ${ }^{*}, p<0.05 v s$ control (group 1); ${ }^{* *}, p<0.05 v$ group 3 .

lular $\mathrm{pH}(7,9)$, as well as more extensive neuronal necrosis and infarct size $(4,33,34)$.

${ }^{31} \mathrm{P}-\mathrm{NMR}$ spectroscopy was used in the present study to monitor levels of high-energy phosphates and document the presence of cerebral tissue hypoxia. In addition, we maintained blood glucose concentrations within a target range by using the glucose clamp technique and thus could examine the effects of a specific degree of hyperglycemia. This aspect of the experimental protocol is unique compared with previous studies that used either single doses or continuous infusions of glucose at fixed rates, resulting in glucose concentrations that varied during the experimental period, ranging from 7 to $22 \mathrm{mmol} / \mathrm{L}$ $(13,30,35)$. Rosenberg and Murdaugh (14) used a modified glucose clamp method to attain blood glucose concentrations greater than $11 \mathrm{mmol} / \mathrm{L}$ in newborn lambs but did not maintain glucose within a specified range during the study. The glucose concentration chosen for the clamp in the present study was selected to be well outside the range observed during pilot studies of untreated hypoxia but not high enough to cause osmotic effects. By using the combination of NMR spectroscopy and the glucose clamp, we were able to ensure comparable degrees of insult between the two hypoxic groups of animals and consistent treatment in the hyperglycemia/hypoxia group.

Several mechanisms could contribute to the reported differences in the effect of hyperglycemia on hypoxia/ischemia in the adult and newborn brain. During ischemia, the reduction in 
cerebral blood flow decreases delivery of oxygen, glucose, and other metabolic substrates while allowing accumulation of metabolic products such as lactate and $\mathrm{H}^{+}(36)$. In the newborn, the effect of decreased substrate availability with subsequent energy depletion may be more critical than the accumulation of lactate and development of tissue acidosis (17). Hyperglycemia may be associated with better preservation of levels of high-energy phosphates during hypoxia/ischemia in both adults (37) and newborns (29), although Wagner et al. (4) found no difference in ATP levels during ischemia in hyperglycemic versus normoglycemic adult cats. The study design used in the present investigation precluded measurement of the effect of hyperglycemia on preservation of cerebral levels of high-energy phosphates during hypoxia, inasmuch as $\mathrm{FiO}_{2}$ was adjusted to produce comparable reductions in $\mathrm{PCr}$ in untreated and hyperglycemic animals (Fig. 2). As a result, the maintenance of normal $\mathrm{Na}^{+}, \mathrm{K}^{+}$-ATPase activity and prevention of accumulation of lipid peroxidation products in the brain of the hyperglycemic hypoxic animals occurred at levels of $\mathrm{PCr}$ and ATP comparable to those seen in the spectra of the untreated hypoxic animals. It is possible that there were local alterations in concentrations of high-energy phosphates that could not be detected by the methods used. The spectrum obtained using a surface coil as described represents the overall average value for each of the metabolites in both gray and white matter within the tissue sampled, whereas energy depletion during hypoxia may occur more rapidly in white matter than in gray matter (38). Hyperglycemia may have preserved ATP and PCr concentrations in white matter, contributing to the present results.

Hyperglycemia may ameliorate hypoxia-induced changes in brain cell membrane structure and function by increasing free radical scavenging by the glutathione peroxidase/glutathione reductase system. Oxygen free radicals produced during cerebral hypoxia (39-41) can generate lipid hydroperoxides in cell and mitochondrial membranes, altering membrane structure and fluidity (42), or denature and crosslink proteins, altering receptor and enzyme function (43). Glutathione acts to repair oxidant injury by undergoing oxidation while reducing lipid hydroperoxides present in cell membranes. NADPH produced via the pentose phosphate pathway is required to recycle oxidized glutathione, thus maintaining the pool of GSH to provide continued antioxidant activity. Depletion of NADPH is associated with decreased concentrations of GSH as well as an enhanced response to oxidant stress in hepatocytes (44). In disorders associated with impaired mitochondrial oxidative metabolism, membrane lipid peroxides are elevated and GSH levels are diminished (45), further supporting the link between oxidative metabolism and antioxidant activity. Studies using tracer methodology have demonstrated that the activity of the pentose phosphate pathway is increased in adult rats during hypoxia, suggesting that the demand for reduced glutathione is increased during hypoxia (46). Although increased glucose during hypoxia could increase the rate of free radical production via incompletely oxidized electron-transport-chain intermediates by increasing the rate of anaerobic glycolysis, an elevated glucose concentration could also lead to increased availability of reduced glutathione for repair of free radicalinduced membrane changes.
Hyperglycemia may also be neuroprotective by reducing the excitotoxic effects of glutamate released during hypoxia. Activation of the $N$-methyl-D-aspartate receptor-ion channel complex by glutamate during hypoxia leads to increased intracellular $\mathrm{Ca}^{++}$, initiating a cascade of alterations of cell function (47). Reuptake of extracellular glutamate by astrocytes, a normal mechanism for preventing excitotoxicity, appears to be dependent on the availability of glucose (48). Decreased $\mathrm{Na}^{+}, \mathrm{K}^{+}$-ATPase activity may reduce $\mathrm{Ca}^{++}$efflux via the $\mathrm{Na}^{+}-\mathrm{Ca}^{++}$exchanger (49), further contributing to increased intracellular $\mathrm{Ca}^{++}$. Maintenance of normal ion flux via the $\mathrm{Na}^{+}, \mathrm{K}^{+}$-ATPase could serve indirectly to reduce the effects of increased $N$-methyl-D-aspartate receptor activity by preserving the ionic gradients needed for $\mathrm{Na}^{+}-\mathrm{Ca}^{++}$exchange.

Although the blood glucose concentration in the untreated hypoxic animals increased significantly from 4.6 to 8.8 $\mathrm{mmol} / \mathrm{L}$ after the onset of hypoxia, it remained significantly lower than the concentration maintained during the glucose clamp and hyperglycemia/hypoxia periods in group 4 piglets. The spontaneously occurring increase in blood glucose to this mildly hyperglycemic level was associated with brain cell membrane dysfunction, suggesting that there may be a threshold glucose concentration necessary to achieve the apparent protective effect on brain cell membrane function observed in group 4. LeBlanc et al. (35) reported that neurologic outcome was worse in newborn piglets that were hyperglycemic during hypoxia/ischemia. However, blood glucose in that study was $12 \mathrm{mmol} / \mathrm{L}$ at the start of hypoxia/ischemia, reaching concentrations of $20 \mathrm{mmol} / \mathrm{L}$ only during the last $5-10 \mathrm{~min}$ of the insult. The finding of increased injury under "nonclamped" hyperglycemia further supports the hypothesis that glucose is protective only if blood glucose concentrations are above a certain threshold level. Additional experiments using the same model and maintaining specific blood glucose concentrations over a range of selected values will be needed to answer this question.

In conclusion, the data presented here demonstrate that the changes in brain cell membrane structure and function observed during an acute episode of cerebral hypoxia in the newborn piglet are reduced if hypoxia occurs during an acute period of hyperglycemia. These findings, as well as studies in other models, suggest that it may be necessary to reevaluate the glucose requirement for maintenance of normal cerebral function in the immature brain at risk for acute hypoxic events.

\section{REFERENCES}

1. Corbett RJT, Laptook AR, Nunnally RL, Hassan A, Jackson J 1988 Intracellular pH, lactate, and energy metabolism in neonatal brain during partial ischemia measured in vivo by ${ }^{31} \mathrm{P}$ and ${ }^{1} \mathrm{H}$ nuclear magnetic resonance spectroscopy. J Neurochem 51:15011509

2. Lundgren J, Mans A, Siesjö BK 1990 Ischemia in normoglycemic and hyperglycemic rats: plasma energy substrates and hormones. Am J Physiol 258:E767-E774

3. Rehncrona S 1985 Brain acidosis. Ann Emerg Med 14:770-779

4. Wagner KR, Kleinholz M, de Courten-Myers GM, Myers RE 1992 Hyperglycemic versus normoglycemic stroke: topography of brain metabolites, intracellular $\mathrm{pH}$, and infarct size. J Cereb Blood Flow Metab 12:213-222

5. Moore TJ, Lione AP, Regen DM, Tarpley HL, Raines PL 1971 Brain glucose metabolism in the newborn rat. Am J Physiol 221:1746-1753

6. Sieber FE, Traystman RJ 1992 Special issues: glucose and the brain. Crit Care Med 20:104-114

7. Chopp M, WeIch KMA, Tidwell BS, Helpern JA 1988 Global cerebral ischemia and intracellular $\mathrm{pH}$ during hyperglycemia and hypoglycemia in cats. Stroke 19:13831387 
8. Lundgren J, Cardell M, Wieloch T, Siesjö BK 1991 Preischemic hyperglycemia and postischemic alteration of rat brain pyruvate dehydrogenase activity. J Cereb Blood Flow Metab 10:536-541

9. Combs DJ, Dempsey RJ, Maley M, Donaldson D, Smith C 1990 Relationship between plasma glucose, brain lactate, and intracellular $\mathrm{pH}$ during cerebral ischemia in gerbils. Stroke 21:936-942

10. Smith M-L, von Hanwehr R, Siesjö BK 1986 Changes in extra- and intracellular pH in the brain during and following ischemia in hyperglycemic and in moderately hypoglycemic rats. J Cereb Blood Flow Metab 6:574-583

11. Myers RE, Yamaguchi S 1977 Nervous system effect of cardiac arrest in monkeys. Arch Neurol 34:65-74

12. Myers RE 1976 Anoxic brain pathology and blood glucose. Neurology 26:345-350

13. Hope PL, Cady EB, Delpy DT, Ives NK, Gardiner RM, Reynolds EOR 1988 Brain metabolism and intracellular $\mathrm{pH}$ during ischaemia: effects of systemic glucose and bicarbonate administration studied by ${ }^{31} \mathrm{P}$ and ${ }^{1} \mathrm{H}$ nuclear magnetic resonance spectroscopy in vivo in the lamb. J Neurochem 50:1394-1402

14. Rosenberg AA, Murdaugh E 1990 The effect of blood glucose concentration on postasphyxia cerebral hemodynamics in newborn lambs. Pediatr Res 27:454-459

15. Laptook AR, Corbett RJT, Nunnally RL 1990 Effect of plasma glucose concentration on cerebral metabolism during partial ischemia in neonatal piglets. Stroke 21:435440

16. Holowach-Thurston J, Hauhart RE, Jones EM 1974 Anoxia in mice: reduced glucose in brain with normal or elevated glucose in plasma and increased survival after glucose treatment. Pediatr Res 8:238-243

17. Vannucci RC, Yager JY 1992 Glucose, lactic acid, and perinatal hypoxic-ischemic brain damage. Pediatr Neurol 8:3-12

18. Mishra OP, Delivoria-Papadopoulos $\mathrm{M} 1988 \mathrm{Na}^{+}, \mathrm{K}^{+}$-ATPase in developing fetal guinea pig brain and the effect of maternal hypoxia. Neurochem Res 13:765-770

19. Mishra OP, Delivoria-Papadopoulos M 1989 Lipid peroxidation in developing fetal guinea pig brain during normoxia and hypoxia. Dev Brain Res 45:129-135

20. DiGiancomo JE, Pane CR, Gwiazdowski S, Mishra OP, Delivoria-Papadopoulos M 1992 Effect of graded hypoxia on brain cell membrane injury in newborn piglets. Biol Neonate 61:25-32

21. DeFronzo RA, Tobin JD, Andres R 1979 Glucose clamp technique: a method for quantifying insulin secretion and resistance. Am J Physiol 237:E214-E223

22. Hay Jr WW, Meznarich HK 1986 The effect of hyperinsulinemia on glucose utilization and oxidation and on oxygen consumption in the fetal lamb. Q J Exp Physiol 71:689-698

23. Younkin DP, Wagerle LC, Chance B, Maris J, Delivoria-Papadopoulos M 1984 NMR spectroscopic studies of metabolic changes during graded hypoxia in newborn lambs. J Physiol 62:1569-1574

24. Bailey IA, Williams SR, Radda GK, Gadian DG 1981 Activity of phosphorylase in global ischemia in the rat brain. Biochem J 196:171-178

25. Harik SI, Doul GH, Dick APK 1985 Specific ouabain binding to brain microvessel and choroid plexus. J Cereb Blood Flow Metab 5:156-160

26. Folch-Pi J, Lees MJ, Sloane-Stanley GH 1957 A simple method for the isolation and purification of total lipids from animal tissue. J Biol Chem 226:497-409

27. Recknagel RO, Glende Jr EA 1984 Spectrophotometric detection of lipid conjugated dienes. Methods Enzymol 105:331-337

28. Dillard CJ, Tappel AL 1984 Fluorescent damage products of lipid peroxidation Methods Enzymol 105:337-341

29. Laptook AR, Corbett RJT, Arencibia-Mireles O, Ruley J 1992 Glucose-associated alterations in ischemic brain metabolism of neonatal piglets. Stroke 23:1504-1511
30. Voorhies TM, Rawlinson D, Vannucci RC 1986 Glucose and perinatal hypoxicischemic brain damage in the rat. Neurology 36:1115-1118

31. Chan PH, Fishman RA, Longar S, Chen S, Yu A 1985 Cellular and molecular effects of polyunsaturated fatty acids in brain ischemia and injury. Prog Brain Res 63:227235

32. Pastuszko A, Erecinska M, Wilson DF, Silver IA 1985 Some effects of ischaemia and hyperglycaemia on neurotransmitter metabolism in rat brain. Neurol Res 7:120-128

33. Hoffman WE, Braucher E, Pelligrino DA, Thomas C, Albrecht RF, Miletich DJ 1990 Brain lactate and neurologic outcome following incomplete ischemia in fasted, nonfasted, and glucose-loaded rats. Anesthesiology 72:1045-1050

34. Pulsinelli WA, Waldman S, Rawlinson D, Plum F 1983 Moderate hyperglycemia augments ischemic brain damage: a neuropathologic study in the rat. Neurology 33:222-233

35. LeBlanc MH, Huang M, Vig V, Patel D, Smith EE 1993 Glucose affects the severity of hypoxic-ischemic brain injury in newborn pigs. Stroke 24:1055-1062

36. Welsh FA, Greenberg JH, Jones SC, Ginsberg MD, Reivich M 1980 Correlation between glucose utilization and metabolite levels during focal ischemia in cat brain. Stroke 11:79-84

37. Folbergrova J, Memezawa H, Smith M, Siesjö BK 1992 Focal and perifocal changes in tissue energy state during middle cerebral artery occlusion in normo- and hyperglycemic rats. J Cereb Blood Flow Metab 12:25-33

38. Duffy TE, Cavazzuti M, Cruz NF, Sokoloff L 1981 Local cerebral glucose metabolism in newborn dogs: effects of hypoxia and halothane anesthesia. Ann Neurol 11:233-246

39. Fridovich I 1979 Hypoxia and oxygen toxicity. Adv Neurol 26:255-266

40. Moss M, Kurzner S, Razlog Y, Lister G 1988 Hypoxanthine and lactate concentrations in lambs during hypoxic and stagnant hypoxia. Am J Physiol 255:H53-H59

41. Vlessis AA, Widener LL, Bartos D 1990 Effect of peroxide, sodium, and calcium on brain mitochondrial respiration in vitro: potential role in cerebral ischemia and reperfusion. J Neurochem 54:1412-1418

42. Villacar A, Spatz M, Dodson RF, Corn C, Bembry J 1989 Effect of arachidonic acid on cultured cerebromicrovascular endothelium: Permeability, lipid peroxidation and membrane "fluidity." Acta Neuropathol 78:310-316

43. Dean RT, Hunt JV, Grant AJ, Yamamoto Y, Niki E 1991 Free radical damage to proteins: the influence of the relative localization of radical generation, antioxidants, and target proteins. Free Radic Biol Med 11:161-168

44. Tribble DL, Jones DP 1991 Oxygen dependence of oxidative stress. Rate of NADPH supply for maintaining the GSH pool during hypoxia. Biochem Pharmacol 729-736

45. Piccolo G, Banfi P, Azan G, Rizzuto R, Bisson R, Sandona D, Bellomo G 1991 Biological markers of oxidative stress in mitochondrial myopathies with progressive external ophthalmoplegia. J Neurol Sci 105:57-60

46. Hakim SM, Moss G, Gollomp SM 1976 The effect of hypoxia on the pentose phosphate pathway in brain. J Neurochem 26:683-688

47. Choi DW 1990 Cerebral hypoxia: some new approaches and unanswered questions. J Neurosci 10:2493-2501

48. Swanson RA, Chen J, Graham SH 1994 Glucose can fuel glutamate uptake in ischemic brain. J Cereb Blood Flow Metab 14:1-6

49. Lees GJ 1991 Inhibition of sodium-potassium-ATPase: a potentially ubiquitous mechanism contributing to central nervous system neuropathology. Brain Res Rev $16: 283-300$ 